\title{
Editorial: urban identity versus globalisation
}

Derya Oktay BArch, MSc in Arch, PgDipUD, PhD

Dean, Faculty of Architecture, Ondokuz Mayis University, Samsun, Turkey

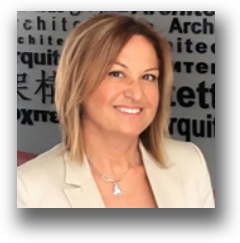

In the first part of this special issue, published in December 2016, the presented papers explored various notions of urban identity in contemporary cities. Cities which have experienced dramatic change due to the pressure of accommodating increasingly concentrated populations, dominance of vehicular movement and inappropriate urban planning approaches (Oktay, 2016: pp. 255). The papers, in this context, focused on the issues of multicultural and heterogeneous cities, city centres against consumer culture, place making and reclaiming the public realm in cities, and management and conservation of local heritage and values in cities in transformation.

In this second volume, the concept of urban identity has been addressed from different perspectives considering its meaning and significance in the changing context of the city, its perception by different groups of people, its reflection in public open spaces, and how the experience of a place can be enriched by the use of technology.

In the opening paper, Oktay (2017) posits that effective urban design policies and strategies have the potential to reinforce local character and create places with identity; accordingly, a thorough analysis of the concept of identity is needed and an understanding of the ways through which it can be achieved without reducing the concept to an aesthetic dressing, possesses a great significance. Based on a comprehensive review of the literature and the findings of the author's previous surveybased research (Oktay and Bala, 2015: pp. 202-203), together with the results of observations (through an urban designer's eyes) of more than fifty cities in thirty countries, she claims that the most powerful elements contributing to the identity of the city are natural environment, social-cultural environment, identifiable quarters, public spaces, and in some cases, landmarks.

What is also emphasized in this paper is that, as cities are always changing and evolving in response to social, economic and political forces, the urban environment must be considered from a time-based perspective, identifying the changes in the local context. In line with these, this paper searches for urban identity by focusing on the organizing elements both in theory and practice. Exploring the elements of identity in Samsun, a big harbour city in Turkey, with a rich cultural background where transformations are dramatic, the study concludes with strategic ideas and proposals in order to sustain and enhance the urban identity of this city and cities going through similar transformations.

Fátima Bernardo, Joana Almeida and Catarina Martins (Bernardo et al, 2017), in their paper on urban identity and tourism, focus on a critical issue regarding how to overcome tourism impacts on the authenticity of a place and the local residents. Highlighting the significance of the interdependence between identity as perceived by tourists and the identity of the residents rooted in their relationship with the place. They propose an actor-oriented approach towards creating and maintaining urban identity in order to understand the process, and to produce knowledge for informed action. Reviewing the relevant literature on the conceptualisation of urban identity and addressing the mentioned issues in the context of the growing attractiveness of Lisbon, Portugal, they use the historic neighbourhood Alfama as a case study. The study reveals the effects of architecture and social activity patterns on the authenticity of the place, and proves that different groups who contribute to the urban identity of a place are characterized by a set of parameters, such as their social and cultural backgrounds and their degrees of involvement with the place.

The acceleration of globalisation has initiated a process of urban transformation, posing some serious threats and challenges to the public spaces of cities. As cities have grown larger and spread wider, urban functions have disintegrated and public spaces, which are important to a democratic and inclusive society, have lost much of their significance in urban life. They have become empty spaces, spaces of abstract freedom but no enduring human connection (Sennett, 1994: 375; 
Oktay, 2011: 21). Since public spaces are most of what we see and provide much of the information by which we characterize the locale within the city, we should unquestionably use their potential to the full through enhancing their quality as places for people. In this vein, in their paper, Sibel Polat and Neslihan Dostoglu's (Polat and Dostoglu, 2017) propose a research method for monitoring identity in public open spaces via a case study of Republic Square, Bursa, Turkey. To determine the dimensions of place identity, they have developed a research method to measure the dimensions that are more important in defining place identity of public open spaces. Studying the historical background of the square and the milestones in the history of the area, the authors accommodate a quantitative and qualitative survey for each defined period, and make interpretations about how the identity of a place changes from the past to the present in line with the political, economic, demographic and legal-administrative conditions.

Finally, as a reflection of technological advancements in the era of globalisation, Marichela Sepe (Sepe, 2017) dwells on the idea that user experience of a place can be further enhanced and virtualized using smart technologies. She advocates that the experiential itineraries she has proposed would encourage more frequent use by locals and help them identify with the ancient history of their area, in historic towns in particular. This would stimulate the locals to participate more actively in the place's life, and help to avert the threats of globalisation or of the locals' gradual desertion of places, leaving them only to tourists. The author accordingly introduces an analysis and design software tool for identification and enhancement of cultural and identity resources, and applies it in the cases of Palestrina and Gaeta in Italy, in collaboration with the local administrators and computer companies.

Taken together, and based on the experience of an urban design teacher and program and research centre director, it can be asserted that there is a need for a paradigmatic shift in the focus of urban design; a shift away from the compartmentalization of the design framework which encompasses social control, economic efficiency, and spatial order (Oktay, 2015). In this context, urban designers must develop a deeper understanding of the character and identity of place, reading and analysing the landscape not only for visual clues, perceptual richness and use, but also for the cultural background, social messages and meanings. Further, as Lang (2016: pp. 266) posits, "the designing process has to follow a bottom-up as well as a top-down approach to the formation of social policies and to urban design" in order to ensure the development or re-development of cities and urban environments with identity.

\section{REFERENCES}

Bernardo F, Almeida J and Martins C (2017) Urban identity and tourism: different looks, one single place. Proceedings of the Institution of Civil Engineers - Urban Design and Planning 170(5): 205-216, http://dx.doi.org/10.1680/jurdp.15.00036.

Lang TJ (2016) Urban Design in Heterogeneous Cities: Issues and Responses. Proceedings of the Institution of Civil Engineers Urban Design and Planning 169(6): 258-267.

Oktay D (2002) The quest for urban identity in the changing context of the city: Northern Cyprus. Cities 19(4): 31-41.

Oktay D (2011) Sustainable Urbanism revisited: A Holistic Framework Based on Tradition and Contemporary Orientations, in Green and Ecological Technologies for Urban Planning: Creating Smart Cities (Ed: O. Y. Ercoskun), IGI-Global, Pennsylvania, USA, 17-36.

Oktay D (2015) A critical review on the current thought and practice of Urban Design: New roles in the future", ICONARP Journal of Architecture and Planning 3(2): 1-11.

Oktay D (2016) Editorial. Proceedings of the Institution of Civil Engineers - Urban Design and Planning 169(6): 255-257.

Oktay D (2017) Reevaluating urban identity under changing circumstances: The case of Samsun, Turkey. Proceedings of the Institution of Civil Engineers - Urban Design and Planning 170(5): 189-204, http://dx.doi.org/10.1680/jurdp.17.00001.

Polat S and Dostoglu N (2017) Measuring place identity in public open spaces. Proceedings of the Institution of Civil Engineers - Urban Design and Planning 170(5): 217-230, http://dx.doi.org/10.1680/ jurdp.15.00031.

Sennett R (1994) Flesh and Stone: The Body and the City in Western Civilization. WW Norton \& Co., London, UK.

Sepe M (2017) Softly Smart: Experiencing Place Identity. Proceedings of the Institution of Civil Engineers - Urban Design and Planning 170(5): 231-243, http://dx.doi.org/10.1680/jurdp.15.00023. 